Ethiopian Journal of Environmental Studies \& Management 8(1): 81 - 96, 2015.

ISSN:1998-0507

doi: http://dx.doi.org/10.4314/ejesm.v8i1.8

Submitted: November 04, 2014

Accepted: January 16, 2015

\title{
APPRAISAL OF AUTO-RICKSHAW AS POVERTY ALLEVIATION STRATEGY IN NIGERIA: AN EXAMPLE OF LAGOS METROPOLIS
}

\author{
*RAJI, B.A. \\ Department of Geography and Regional Planning, Faculty of Social and Management \\ Sciences, Olabisi Onabanjo University Ago-Iwoye, Ogun State, Nigeria \\ Email: rajbasholaniyi@yahoo.co.uk
}

\begin{abstract}
The study examines the use of auto-rickshaw (three - wheeled cycle) as poverty alleviation scheme in metropolitan areas of Lagos state Nigeria, with the aim of exploring the significance of the scheme in solving beneficiaries' financial challenges. Data were obtained from secondary and primary sources. 200 structured questionnaires were randomly administered to the tricycle operators in 24 stratified loading points in the metropolitan area and information collected were analysed using descriptive and inferential statistical techniques. Findings showed that $73.5 \%$ operators benefited and $26 \%$ did not benefit from the scheme. The study also revealed that male operators (97.3\%) dominated the scheme. Average daily income of the operators is more than N2000 (13USD) while daily operating costs was A1610 (11USD). There is a significant difference in financial difficulty of the operators $\left(t_{c}=1.695, p \leq 0.05\right)$ in post-procurement of the scheme. Despite a positive change in financial situations of operators at post-procurement of NAPEP tricycles $\left(X_{C}^{2}=38.50, p \leq 0.05\right)$ and $81 \%$ operators' rating of NAPEP tricycles in poverty alleviation, some of the challenges facing the operators include high cost of the tricycle coupled with the unfriendly payback period, extortion from police and local council officials, problem of routes choice and competition with other road users. Based on the helpfulness of the scheme, it is recommended that beneficiaries of the scheme be given loan directly at moderate payback period, provision of parking facilities; educate operators about road safety than extortion by police and local government officials. While the study revealed the benefits and challenges of NAPEP policy regarding tricycles in alleviating monetary challenges of applicants in the state, there is need to address observed challenges in the scheme and as well prevent reoccurrence in the fourth face of the scheme.
\end{abstract}

Key Words: Poverty Alleviation, Auto-rickshaw, Lagos Metropolis, Nigeria.

\section{Introduction}

In Nigeria, the problem of poverty has for a long time been a cause for concern to the government. Initial attention focused on rural development as well as town and country planning as a practical means of dealing with the problem. Thus, the second and fourth national development plans contain both direct and indirect allusions to, as well as objectives of, policies and programmes aimed at minimizing the causes of poverty. Several factors which include low productivity, market imperfections, structural shifts in the 
economy, inadequate commitment to programme implementation, political instability, etc., are complex and the consequences often reinforce the causes, further impoverishing the people (Obi, 2007).

In a recent survey, Obi (2007) noted that Nigeria's festering poverty profile was described as' "widespread and severe". The report of comparative analysis of welfare ranked Nigeria below Kenya, Ghana and Zambia and expressed concern over the dwindling purchasing power of the people and the increasing income inequality in Nigeria.

Nigeria is enormously endowed with human, agricultural, petroleum, natural gas, and massive untapped mineral resources. Unfortunately, Nigeria is grouped as one of the poorest counties at the threshold of the $21^{\text {st }}$ century, when ironically she was ranked among the richest 50 in the early 1970s (Obadan, 2004).

The increasing poverty level in the country necessitated the introduction of poverty alleviation programmes by successive governments in the country. But with recent declaration of the reduction in the incidence of poverty level from $70 \%$ to 50\% (Kpakol, 2011), this study therefore examines the use of Auto-rickshaw (Keke $N A P E P)$ as one of the various strategies employed by the National Poverty Alleviation Programme (NAPEP) in the country.

Aregbesola (2009) was of the opinion that Nigerian government should stop the proposition of motorcycle riding and procurement of three wheeler motorcycles as a way of alleviating poverty because they hardly make people rise above poverty; rather they lead to loss of many lives. Aibieyi, and Dirisu (2010) observed that all poverty alleviation programmes in Nigeria have not been successful due to re- occurrence of similar factors that makes the programmes unsuccessful. Agbi (2014) however noted that though NAPEP is a laudable programme meant for the poor across the federation, it could avoid proper monitoring, evaluation, commitment and reprimanding for lacking legal backing.

Agbiokoro (2010) stated that in spite of the problems facing the implementation of NAPEP as poverty eradication programmes in Nigeria, NAPEP seems to have impacted significantly positive on the economics of Nigeria. Owoeye (2009) also observed that irrespective of gender, Keke NAPEP has been a source of income generation for both the poor and the University graduates.

Contributions to NAPEP by the scholars above revealed divergent views on its relevance. In the light of this, this study is set to examine the significance of NAPEP through 'Keke NAPEP' in easing the socio-economic challenges of the beneficiaries of the scheme.

Direct and indirect involvement of government in the provision of transportation is well established the world over (Raji, 2009; Raji and Otun, 2008). The global economic recession and the fall out of Structural Adjustment Programme (SAP) between 1987 and 1993 in Nigeria greatly affect the purchasing power of government and the populace to replace existing public transport fleet of buses and taxis (Adeniji, 1982; Oyesiku, 2001; Oyesiku and Odufuwa, 2002).

In order to meet the transport needs of people, motorcycle popularly called ('okada' or 'zemidjan') which is commonly used as means of inter-city transport in the riverine areas of the country surfaced as commercial transport system in most urban areas of the country. And this has come to stay in most West- African states.

With the externalities of motorcycles such as road traffic accidents, robberies and 
so on, there is also the need to complement existing public transport and as well create jobs for people of Lagos, about 500 units of auto-rickshaw tricycles was brought in March, 1998 to Lagos state and these was called 'Keke Marwa' named after the then military governor of Lagos state Colonel Buba Marwa who initiated the use of tricycle as a means of transportation in the Lagos metropolis (Owoyele, 2009).

One way to empower people is by creating employment that can give them income. Using Keke NAPEP for commercial transportation is one of the poverty alleviation strategies that the Federal Government employed through National Poverty Eradication Programme in creating employment for the unemployed. The study therefore focuses on Keke NAPEP operators' activities, with the view to explore the significance of the scheme in alleviating beneficiaries' socio-economic challenges.

\section{Methodology}

\section{The Study Area}

This study was based on the study of auto-rickshaw (tricycles) operators in Alimosho Local Government Area of Lagos State (figure 1). Alimosho Local Government is one of the twenty Local
Government Areas in Lagos State (figure 2). Alimosho lies is between Latitudes $6^{0}$ $36^{\prime}$ and $38^{\prime}$ and Longitude $3^{\circ} 17^{\prime}$ and $45^{\prime}$. It is bounded in the North by Ifako-Ijaye Local Government, south by Ojo and Amuwo-Odofin Local Governement Areas, East by Agege, Ikeja and Oshodi-Isolo Local Government Areas and in the west by Ogun State. The Local Government is the largest metropolitan area in Lagos state with population of about 1,277,714 inhabitants (NPC, 2006). Figure 3 shows the loading points of the tricycle operators in the Local Government Area of the state.

Although, the actual number of NAPEP tricycle operators in Lagos state was not known but they can be seen in many parks of fringe settlements such as Ipaja, Ayobo, Ikotun, Ijekun, Iseri-Oshun, Idimu, Egbeda, Aboru, Shasha in the Local Government Area. These settlements are evolving as urban area and as well faced with inadequate transportation facilities enjoyed by other metropolitan areas in the state (Raji, 2009). The choice of Alimosho thus stems from preliminary investigation which revealed that the Local Government Area has the largest concentration of NAPEP tricycle operators and numerous low income earners in Lagos state. 
Appraisal of Auto-Rickshaw as Poverty Alleviation Strategy in Nigeria................RAJI

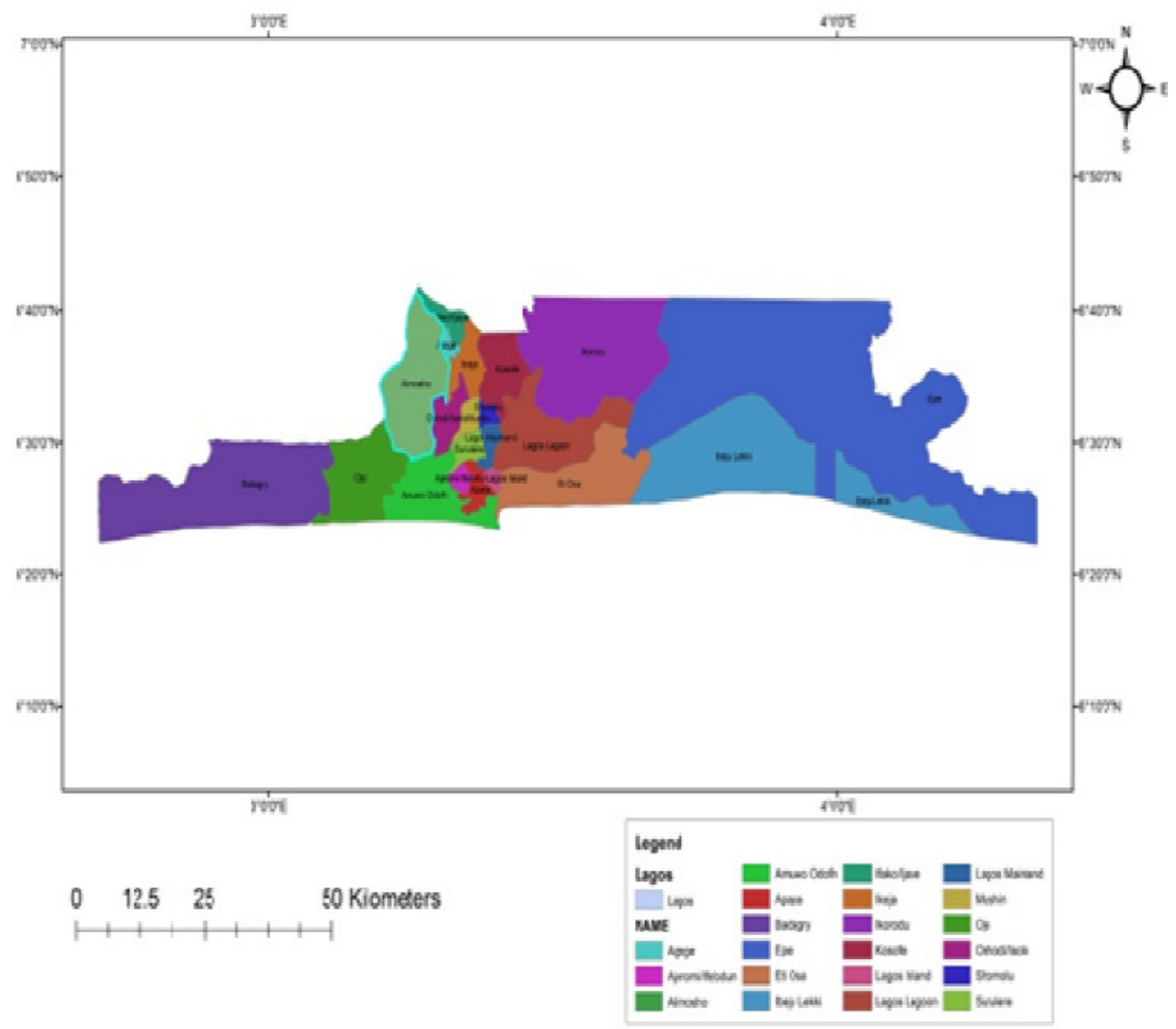

Figure 1: Lagos state Map 
Ethiopian Journal of Environmental Studies and Management Vol. 8 no. 12015

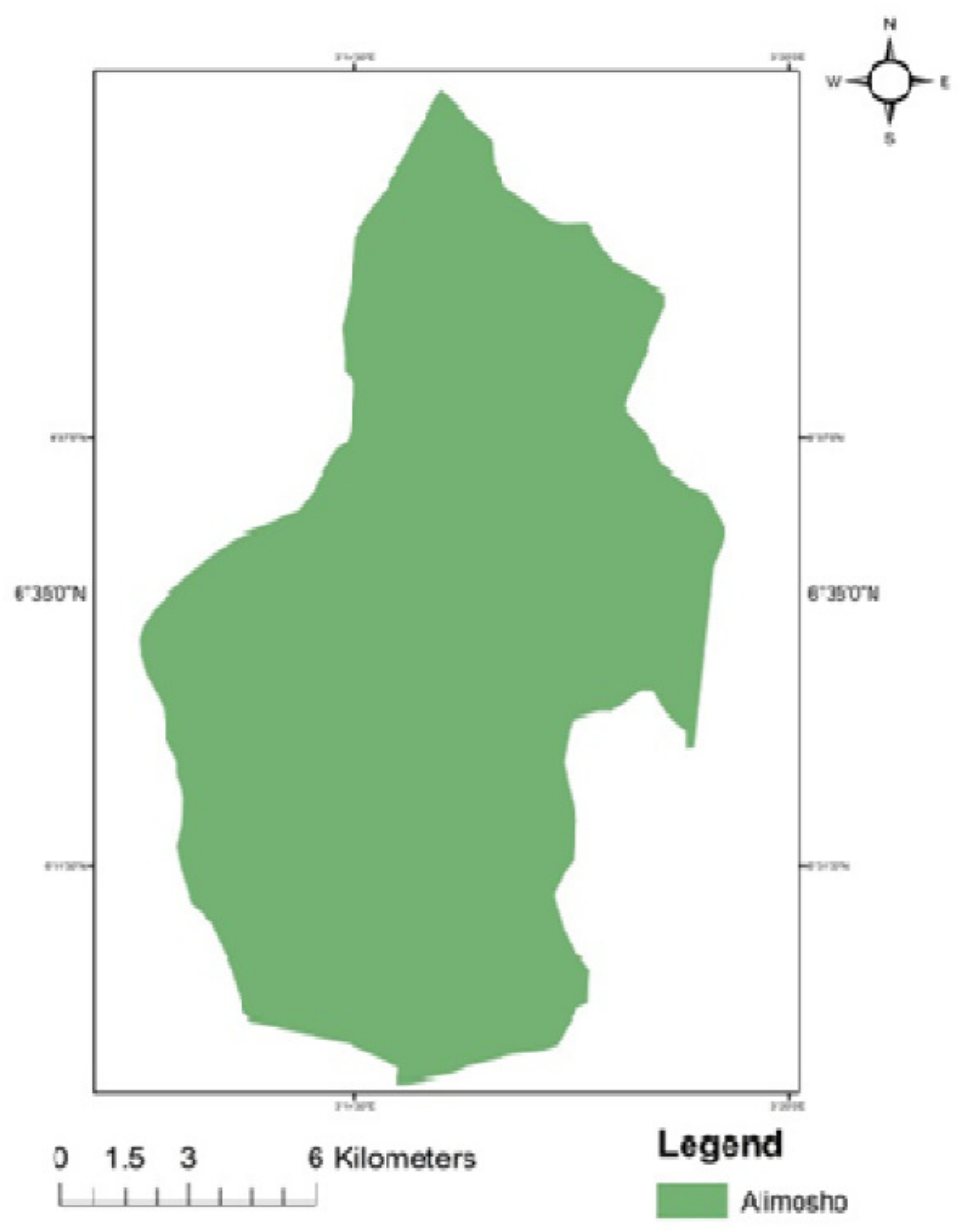

Figure 2: Map of Alimosho 

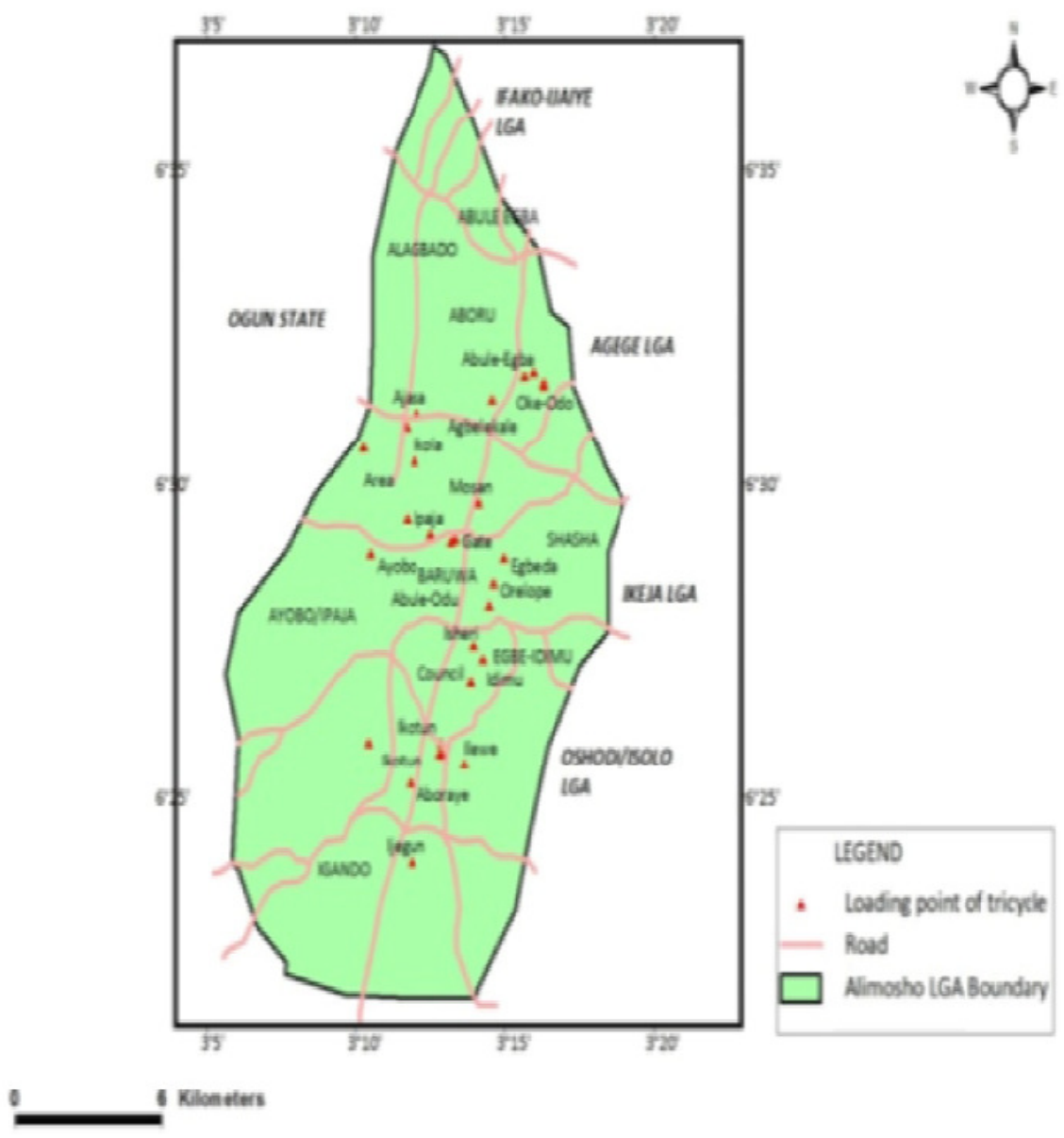

Figure 3: Map of Alimosho with Tricycle Loading Points

\section{Research Design}

The research design used for the study is survey designs which involve explanatory design. Information was obtained from tricycle operators in relation to the research questions through a wellstructured questionnaire. Thereafter, information collected from the tricycle operators was used in presenting the results of the study. A two-staged sampling technique was used. Loading points of tricycle operators in Alimosho Local Government Area was stratified into 24 loading points. In each of the loading points, questionnaires were randomly administered

\section{Sources of Data}

Data used for the study were collected from both secondary and primary sources. Secondary data such as Annual Abstract of Statistics, Technical Reports, Academic Journals and other periodic publications about Lagos State, the metropolitan area and tricycle operations were used. Information obtained includes historical development of poverty alleviation programme and the advent of auto rickshaw in Lagos state. Primary data used to complement secondary sources in the study was questionnaire and some of the questions asked include tricycle operators' socio-economic characteristics, housing situation, type of ownership, years of 
operations, daily average income and operating costs, pre and post financial situation and some of the challenges encountered.

\section{Study Population Sample Size}

The tricycle operators in Alimosho Local Government Area of Lagos State have an estimated population of three hundred and nineteen (319). However, two hundred (200) operators were sampled and technique used was proportional allocation. In proportional allocation, Thomsen (1976), Sukhatme et al. (1984), Okafor (2002), Raji (2013) and Raji et al. (2014) observed that the stratum sample is selected such that the size of the sample is proportional to the total number of units in each stratum, such that $n_{h} \alpha N_{h}$ or $n_{h} \alpha W_{h}$ If the total sample that is to be allocated is $(n)$, then the stratum sample is given as:

$n_{h}=\frac{n}{N} N_{h}=n W_{h}$

Where $n_{h}=$ Stratum sample size

$n=$ Total number of sample to be allocated (in this case, $n=150$ )

$N_{h}=$ Units or stratum of the anticipated population (sample size $=200$ )

$N=\quad$ Observed total population (estimated population $=319)$

The result is shown in table 1 .

Table 1: Locations of Loading Points of Auto-rickshaw, Estimated Population of Operators their sample size at each location

\begin{tabular}{|c|c|c|c|}
\hline Locations & $\begin{array}{l}\text { Estimated Population } \\
(N)\end{array}$ & $\begin{array}{l}\text { Sample Size } \\
\left(N_{h}\right)\end{array}$ & $\begin{array}{l}\text { Total Questionnaires } \\
\text { Obtained }\end{array}$ \\
\hline 1 & 7 & 4 & 4 \\
\hline 2 & 10 & 6 & 6 \\
\hline 3 & 15 & 9 & 9 \\
\hline 4 & 11 & 7 & 7 \\
\hline 5 & 8 & 5 & 5 \\
\hline 6 & 20 & 13 & 13 \\
\hline 7 & 14 & 9 & 9 \\
\hline 8 & 16 & 10 & 10 \\
\hline 9 & 18 & 11 & 11 \\
\hline 10 & 10 & 6 & 6 \\
\hline 11 & 21 & 13 & 13 \\
\hline 12 & 12 & 8 & 8 \\
\hline 13 & 16 & 10 & 10 \\
\hline 14 & 10 & 6 & 6 \\
\hline 15 & 12 & 8 & 8 \\
\hline 16 & 14 & 9 & 9 \\
\hline 17 & 18 & 11 & 11 \\
\hline 18 & 22 & 14 & 14 \\
\hline 19 & 16 & 10 & 10 \\
\hline 20 & 18 & 11 & 11 \\
\hline 21 & 10 & 6 & 6 \\
\hline 22 & 6 & 4 & 4 \\
\hline 23 & 9 & 6 & 6 \\
\hline 24 & 6 & 4 & 4 \\
\hline Total & 319 & 200 & 200 \\
\hline
\end{tabular}

\section{Data Analysis}

Thereafter, information obtained were analysed using both qualitative and quantitative approaches. Descriptive statistics such as frequency tables, percentages and averages as well as 
inferential statistics (Chi-Square and Student- $t$ ) were used in the presentation of the findings.

\section{Results and Discussion}

Operators Socio-economic Characteristics

Table 2 shows socio-economic characteristics of the tricycle operators interviewed in the study area. Majority of the tricycle operators in the study area are male $(97.3 \%)$ and married $(86.4 \%)$. The distribution of tricycle operators based on household size shows that $1.4 \%$ of the operators have household size of one, $21.8 \%$ have household size of two, $16.3 \%$ have household size of three and $60.5 \%$ of the tricycle operators have household size is more than three.

Table 2: Socio-Economic Characteristics of Tricycle Operators

\begin{tabular}{l|ll}
\hline Variables & Freq & \% \\
\hline Gender & 143 & \\
Male & 4 & 97.3 \\
Female & & 2.7 \\
Marital Status & 6 & \\
Single & 127 & 4.1 \\
Married & 11 & 86.4 \\
Divorced & 3 & 7.5 \\
Widowed & & 2.0 \\
Household size & 2 & \\
One & 32 & 1.4 \\
Two & 24 & 21.8 \\
Three & 89 & 16.3 \\
More than three & & 60.5 \\
Age (Years) & 15 & \\
20 - 30 & 87 & 10.2 \\
31 - 40 & 35 & 59.2 \\
41 - 50 & 7 & 23.8 \\
51 - 60 & 3 & 4.8 \\
Above 60 & & 2.0 \\
Level of Education & 64 & \\
No formal education & 61 & 32.0 \\
Having primary education & 50 & 30.6 \\
Having secondary education & 25 & 25.2 \\
Having post-secondary education & & 12.2 \\
\hline & & \\
\hline
\end{tabular}

Categorising the tricycle operators in the study area according to their age, the distribution showed that majority of the tricycle operators $(69.4 \%)$ are in the working class group between (20-40) years. Distribution of the tricycle operators in the study area according to their level of education shows that $32.0 \%$ of the operators are not educated in any form, $30.6 \%$ have primary school education,
$25.2 \%$ have secondary school education and $12.2 \%$ of the operators have postsecondary school education. The result shows that large numbers of the operators $68.0 \%$ have one form of education or the other.

The poor in Nigeria are not a homogeneous group as observed by Obi (2007), though this study is based on tricycle operators a homogenous group but 
there are variations in their socio-economic status. For example, evidence from the World Bank poverty assessment on Nigeria using 1992/93 household survey data, shows that the nature of those in poverty can be distinguished by the following characteristics: sector, education, age, gender and employment status, of the head of household and the household size (Federal Office of Statistics,1995) as shown in table 3.

Table 3: Poverty incidence by socio-economic groups, 1996/97

\begin{tabular}{l|lll}
\hline Socio-economic groups & Extreme poor & Moderate poor & Non-poor \\
\hline Urban & 25.2 & 33.0 & 41.8 \\
Rural & 31.6 & 38.2 & 30.7 \\
Male-headed & 29.8 & 36.7 & 33.6 \\
Female-headed & 25.0 & 33.5 & 41.5 \\
Age of head & & & \\
$15-24$ & 16.2 & 21.2 & 62.6 \\
$25-34$ & 20.2 & 32.5 & 47.3 \\
$35-44$ & 27.9 & 36.7 & 35.4 \\
$45-54$ & 32.7 & 38.6 & 28.7 \\
$55-64$ & 32.6 & 37.3 & 30.1 \\
65 and above & 33.5 & 34.6 & 32.0 \\
Education of head & & & \\
Non & 34.3 & 38.3 & 27.4 \\
Primary & 24.3 & 35.1 & 40.6 \\
Secondary & 21.2 & 30.8 & 48.0 \\
Post-secondary & 15.3 & 32.9 & 51.8 \\
\hline S
\end{tabular}

Source: Federal Office of Statistics (1999), adapted from Fiscal policy and poverty alleviation: Some policy options for Nigeria by Obi (2007).

The result of the finding regarding the level of education of the tricycle operators in table 2 shows a resemblance with the statistics obtained by Federal Office of Statistics (1999) (table 3) which indicated that large proportion of people that are extremely poor, people that are moderately poor and non-poor with values $65.7 \%$, $61.7 \%$ and $72.6 \%$ respectively have one form of education or the other.

\section{Housing Situations of Operators}

The distribution of tricycle operators according to their housing situations is presented in table 4.The results shows that $15.6 \%$ of the tricycle operators live in their personal house, a majority of the operators $62.6 \%$ rent the house they live in, $18.4 \%$ live with a family and $3.4 \%$ of the tricycle operators.

Table 4: Housing Situation of Operators

\begin{tabular}{l|ll}
\hline Variables & Freq & \% \\
\hline Owned a house & 23 & 15.6 \\
Rent a House & 92 & 62.6 \\
Living with a family & 27 & 18.4 \\
No Response & 5 & 3.4 \\
\hline
\end{tabular}

The result in table 4 shows that large numbers of the tricycle operators $(81 \%)$ do not own their own houses and this require payment of house rents and certain responsibilities for those who rent a house and live with a family respectively.

Ownership Type and Number of Tricycles Owned

Table 5 shows the distribution of tricycle operators according to ownership 
type of the tricycle. The result showed that $91.8 \%$ of the respondents owned the NAPEP tricycles while $8.2 \%$ of the do not owned the tricycle.

Table 5: Operators Ownership of Tricycles

\begin{tabular}{l|ll}
\hline Variables & Freq & \% \\
\hline Ownership & & \\
Owned & 135 & 91.8 \\
Do not Owned & 12 & 8.2 \\
Number Owned & & \\
One & 43 & 31.9 \\
Two & 64 & 47.4 \\
Three & 21 & 15.5 \\
More than Three & 7 & 5.2 \\
\hline
\end{tabular}

Out of one hundred and thirty-five operators that owned the tricycle, table 5 revealed that $31.9 \%$ of the operators owned one tricycle, majority (47.4) of the operators sampled owned two tricycles, $15.5 \%$ of the operators owned three tricycles and $5.2 \%$ of the operators sample in the study area owned more than three tricycles.

Years of Operation of Tricycle Operators

An examination of tricycle operators' years of operation, the result in table 6 shows that $7.5 \%$ of the tricycle operators start using 'Keke NAPEP' less than a year during the period of survey, $8.2 \%$ of the operators have spent between 1 to 2 years using the tricycle.

Table 6: Operators Years of Operation

\begin{tabular}{l|ll}
\hline Variables & Freq & \% \\
\hline$<$ 1year & 11 & 7.5 \\
1 - 2 years & 12 & 8.2 \\
3 - 4 years & 48 & 32.6 \\
$5-6$ years & 9 & 6.1 \\
$>$ 6 years & 67 & 45.6 \\
\hline
\end{tabular}

The study further revealed that $32.6 \%$ of the operators sampled in the study area have spent between 3 to 4 years using the tricycle. The distribution also shows that while $6.1 \%$ of the tricycle operators have spent between 5 to 6 years using the tricycle, majority $(45.6 \%)$ of the operators have spent more than 6 years using the tricycle.

Daily Average Income Generated and Operating Costs Incurred by the Tricycle Operators

This study is centre onhow income generated by tricycle operators help in taking care of their live challenges and how this income generation indirectly helps in alleviating their poverty. Thus, table 7 gives information of daily income of tricycle operators and table 8 discusses average daily operating costs of the tricycle operators.

Table 7: Average Daily Income Generating Capabilities of Tricycle Operators

\begin{tabular}{l|ll}
\hline Variables & Freq & \% \\
\hline $\mathrm{N}(1000-2000)$ & 7 & 4.8 \\
$\mathrm{~N}(2001-3000)$ & 36 & 24.5 \\
$\mathrm{~N}(3001-4000)$ & 91 & 61.9 \\
$\mathrm{~N}(4001-5000)$ & 11 & 7.5 \\
$\mathrm{~N}($ Above 5000) & 2 & 1.4 \\
\hline
\end{tabular}

The average daily income rather than average monthly income or average annual income was used in order to make it easier for the operators to be able to recollect the amount they generate. The result shows that $4.8 \%$ of the operators in the study area generate between $\mathbb{N} 1,000: 00$ and $\mathbb{N}$ $2,000: 00,24.5 \%$ of the operators generate between $N$ 2, 001:00 and $N$ 3,000:00, a majority of the operators $(61.9 \%)$ generate between $N$ 3,001:00 and $N$ 4,000:00, 7.5\% of the operators generate between $\mathrm{N} 4$, 001:00 and $N$ 5,000:00, and 1.4\% of the operators generate average daily income above N5,000:00. 
Table 8: Average Daily Operating Costs

\begin{tabular}{l|l}
\hline Variables & Amount \\
\hline Fuel & N910:00 \\
Engine Oil & N $200: 00$ \\
Gear Oil* & N $200: 00$ \\
Police & N $100: 00$ \\
Local & N $100: 00$ \\
Park Ticket & N 100:00 \\
Total Amount & N 1,610:00 \\
\hline \multicolumn{2}{|c}{ *Note: This does not occur on daily basis }
\end{tabular}

In essence, this distribution shows that majority of the operators generate an average of 112, 000 (747USD) monthly, resulting to and average of $\mathrm{N} 1,344,000$ $(8,960$ USD)yearly. The average daily operating costs of the tricycle operators as shown in table 7 revealed a total amount of N 1,610 which amount to $\mathrm{N} 45,080$ (301USD) monthly and $\mathrm{N} 540,960$ $(3,606 \mathrm{USD})$ yearly. The results in table 7 and table 8 show that the tricycle operators' average yearly net income is equivalent to N 803,040 (5,354USD).The results of the net income of the tricycle operators' necessitated the need to look at their financial situations of before and after acquiring the tricycles.

Pre and Post Financial Situations of Tricycle Operators

Table 9 shows the distribution of tricycle operators' financial situations before and after procuring NAPEP tricycles. The distribution shows that 76.4 $\%$ of the operators find it difficult to pay house rent before acquiring NAPEP tricycle; the former reduced from $76.4 \%$ to $43.7 \%$ the later after acquiring NAPEP tricycle. This means that $56.3 \%$ of the operators find it easy to pay house rent after acquiring the tricycle.

Table 9: Financial Situations of Operators Before and After Procuring NAPEP Tricycle

\begin{tabular}{|c|c|c|c|c|}
\hline \multirow[t]{3}{*}{ Variables } & \multicolumn{2}{|c|}{ Before Procurement } & \multicolumn{2}{|c|}{ After Procurement } \\
\hline & Easy & Difficult & Easy & Difficult \\
\hline & $\%$ & $\%$ & $\%$ & $\%$ \\
\hline House Rent & 23.6 & 76.4 & 56.3 & 43.7 \\
\hline Electricity Bills & 56.8 & 43.2 & 92.7 & 7.3 \\
\hline Children School & 3.3 & 96.7 & 54.2 & 45.8 \\
\hline Fees & & & & \\
\hline Medical Bills & 35.7 & 64.3 & 46.8 & 53.2 \\
\hline Other & 43.6 & 56.4 & 67.3 & 32.7 \\
\hline Responsibilities & & & & \\
\hline \multicolumn{5}{|c|}{ Paired Samples Test } \\
\hline & \multicolumn{2}{|c|}{ Before Procurement } & \multicolumn{2}{|c|}{ After Procurement } \\
\hline & $\begin{array}{l}t_{c} \\
-1.345\end{array}$ & $\begin{array}{l}t_{05} \\
0.250\end{array}$ & $\begin{array}{l}t_{c} \\
1.695\end{array}$ & $\begin{array}{l}t_{05} \\
0.165\end{array}$ \\
\hline
\end{tabular}

On payment of electricity bills, the distribution shows that there is a decrease in the difficulty of operators to pay electricity bills from $43.2 \%$ before obtaining NAPEP tricycle to $7.3 \%$ after obtaining the tricycle. The result in table 9shows that on the payment of children school fees, the easiness in the payment of children school fees of the tricycle operators increases from $3.3 \%$ before acquiring NAPEP tricycle to $54.2 \%$ after acquiring the tricycle.

The distribution based on tricycle operators' medical bills shows that $64.3 \%$ 
of the operators find it difficult to pay medical bills before acquiring NAPEP tricycle; the former reduced from $64 \%$ to $53.2 \%$ the later after acquiring NAPEP tricycle. This means that large proportion of the operators still find it difficult to pay medical bills after acquiring the tricycle.

Based on other responsibilities, the distribution shows that there is a decrease in the difficulty of operators to face other responsibilities from $56.4 \%$ before obtaining NAPEP tricycle to $32.7 \%$ after obtaining the tricycle. The result shows that $67.3 \%$ of the operators find it easy to face other responsibilities after acquiring the tricycle. The paired samples test (t-test) conducted financial situations of the operators shows that at the pre-procurement period, there is no significant difference in the financial situations $t_{c}=-1.345$ less than $t_{\mathrm{OS}}=0.250$ but the post-preprocurement period shows a significant difference when $t_{c}=1.695$ greater than $t_{\text {os }}=0.165$.

The average financial situations of NAPEP tricycle operators was computed to give average welfare measure of tricycle operators' pre and post tricycle operations in table 10.The result shows that there is a shift in operators welfare from easy situations of $36.6 \%$ before procurement of tricycle to easy situations of $63.5 \%$.

Table 10: Average Welfare Measure of Pre and Post NAPEP Tricycle Operators

\begin{tabular}{l|ll}
\hline & $\begin{array}{l}\text { Pre-procurement of } \\
\text { NAPEP tricycles } \\
\%\end{array}$ & $\begin{array}{l}\text { Pre-procurement of } \\
\text { NAPEP tricycles } \\
\%\end{array}$ \\
\hline Difficult & 67.4 & 36.5 \\
Easy & $32.6 \quad$ Chi-Square Value & 63.5 \\
& $X_{C}^{2}$ & $X_{05}^{2}$ \\
Ease - Difficulty in Pre and & 38.50 & 3.84 \\
Post Procurement & & \\
\hline
\end{tabular}

The result in table 10 though shows appreciable changes in the financial situations or welfare of the tricycle operators. In order to assert the significance of the observed welfare of the operators, a Chi-Square $\left(X^{2}\right)$ test was conducted. The computation in table 10 shows a significant difference in the observed change difficult financial situations to ease in financial situations when $X_{C}^{2}=38.50$ is greater than $X_{05}^{2}=3.84$. In spite of the positive changes in the operators' financial situations as shown in table 9 and table 10 , section 5.7 examines some of the challenges being faced by the operators.

\section{Challenges Faced by Tricycle operators}

Tricycle operators sampled in the course of this research expressed their challenges in the bid to acquire NAPEP tricycle and in their course of operation. These challenges include cost of procuring the tricycle, routes of operation, size of the tricycle, parking problem and problem involving other road users.

Costs of obtaining the Tricycle: All the operators sampled $(100 \%)$ were of the opinion that the cost of acquiring a tricycle is enormous. They liken the cost of acquiring an auto-rickshaw to buying a fairly used car. The operators explained 
that the tricycles are given out by Microfinance Bank on hire purchase at an average price of $\mathrm{N} 50,000$ and registration

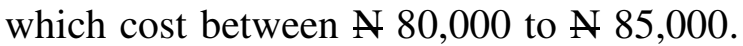
The total of which is equivalent to $\mathrm{N}$ 635,000 (4,233USD).

The study further revealed that NAPEP is to encourage operators to buy through Imitative of Peace Tolerance and Training (IPET), one of its various scheme. IPET procure and sell the tricycle at a unit price

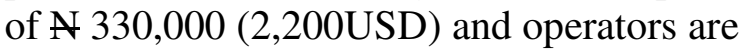
to pay into two different accounts, $\mathrm{N}$ 295,000 (1,967USD) is to be paid into IPET account and $\mathrm{N} 35,000$ is to be paid as commission.

Ironically, NAPEP sells to individual that has the capability to buy the tricycles in fleet at the rate of $N 330,000$ (2,200USD) and these individuals sells to Micro-finance Bank at the rate of $\$ 350,000$ (2,333USD), the bank later sells to tricycle operators at the rate of $\mathrm{N} 550,000$ $(3,667$ USD $)$ in hire purchase and this put additional financial costs of $\mathrm{N} 200,000$ $(1,333$ USD) to the purchase of the tricycle.The operators explained that the actions of NAPEP officials make it difficult to acquire the tricycle at the official price, thereby, questioned the credibility of the programme.

Route Choice, Size of Tricycle and Parking Facilities: From the interview conducted through the use of questionnaire, operators were of the opinion that in many a time, they often ply the route that is economical in order to meet up with the payment of the tricycle. Due to unspecified route, and with the size of the tricycle, they have to share road ways with trucks and other vehicles and this make the operators and passengers vulnerable to road traffic accident. The operators in the study area also lament that, because of uncoordinated tricycle riders association, they lack parks of garages, and many of the operators use roadside as park.

Problems Faced with Other Road Users: Another challenge the tricycle operators are facing is the face of between them and other road users. The distribution in table 11 shows the percentage response of problems faced by tricycle operators in the study area. $11.6 \%$ of the respondents compete with vehicles, $6.8 \%$ of the operators compete with pedestrians when sharing available space on the roadways with pedestrians or when using walkways during congestion, majority of the operators $45.6 \%$ see police as problem because of their extortions, $3.4 \%$ of the operators engage with traders when sharing side roads they use for parking or ran into the traders using side road as market place and $32.6 \%$ of the operators see the extortion and seizure of their tricycle by local government council officials

Table 11: Tricycle Operators contention with other Road Users

\begin{tabular}{l|ll}
\hline Variables & Freq & \% \\
\hline Vehicles & 17 & 11.6 \\
Pedestrians & 10 & 6.8 \\
Police & 67 & 45.6 \\
Traders & 5 & 3.4 \\
Local Council Officials & 48 & 32.6 \\
\hline
\end{tabular}

In spite of the challenges the tricycle operators are facing, operators were asked to assess the significance of National Poverty Alleviation Programme of the auto-rickshaws in poverty reduction through self-empowerment and job creation. The results of the operators response is presented in table 12 .

Overall Assessment of NAPEP AutoRickshaws: The distribution of tricycle operators in response to their overall assessment of NAPEP auto-rickshaw in 
poverty reduction shows that $11.8 \%$ of the operators assessment is excellent, $50.3 \%$ gives the scheme very good rating, $19.1 \%$ of the operators see the programme to be good, $10.2 \%$ of the respondent believe the programme is fair and $8.8 \%$ of the tricycle operators sampled in the study area believe that the scheme performance is poor.

Table 12: Overall Assessment of NAPEP Auto-Rickshaw in Poverty Alleviation

\begin{tabular}{l|ll}
\hline Variables & Freq & \% \\
\hline Excellent & 17 & 11.6 \\
Very Good & 74 & 50.3 \\
Good & 28 & 19.1 \\
Fair & 15 & 10.2 \\
Poor & 13 & 8.8 \\
\hline
\end{tabular}

In spite of the operators' complaints about NAPEP auto-rickshaw scheme, the distribution of the overall assessment of the programme revealed that large number of the operators sampled in the study area $(81 \%)$ still believe that the scheme is reasonable or satisfactory and the positive change in the tricycle operators' difficult situations before and after purchasing the tricycle as shown in table 9 and table 10 earlier confirmed the result of table 12 .

\section{Conclusion and Recommendation}

The study examines tricycle operators who benefited from poverty alleviation scheme termed NAPEP. Findings show that there was an improvement in the welfare of tricycle operators who were involved in the scheme. In spite of the benefits of the scheme, many problems were highlighted by tricycle operators. These problems include (i) high cost of acquiring the tricycle with short term payback period, (ii) problems associated with parking, (iii) continual extortion from the police and local government officials and (iv) conflict with other road users which often results to road traffic accidents. Based on the findings of the study, it is recommended that:

(i) Government should create a way by which beneficiaries of the scheme will obtain the loan directly and payback period be reviewed.

(ii) Adequate parking provision should be made for tricycle operators in various parks where they operate.

(iii)Mechanism should be put in place to curb the police and local government officials in extorting the tricycle operators.

(iv)Enlighten other road users in accommodating tricycle operators on Lagos roads.

(v) Fourth phase of 'Keke NAPEP' must be handled with care in order to sustain the scheme.

Many poverty eradication schemes in Nigeria have failed, the failure stems from the fact that the schemes are forceful in formulation but deficient in implementation. National Poverty Eradication Programme (NAPEP) scheme may be successful and sustain if government at local, state and federal levels permit properimplementation of the scheme.

\section{References}

Adeniji, K. (1982). "Para-transit Modes in Nigeria: Problem and Prospect Cities" The International Quarterly on Urban Policy 4(4) November. 339-347.

Agbi, M.O. (2014). Poverty Alleviation Programme in Nigeria: What Can The Legislature Do? Legislative Digest. 2: 1-5.

Aibieyi, S. and Dirisu, E.O. (2010). National Poverty Alleviation Programmes in Nigeria. Problems and 
Prospects. A Journal of Contemporary Research. Vol. 7. No. 2.

Pp.www.ajol.info/index.php/lwati/iss ue/view/7526

Agbiokoro, T.M. (2010). The Impact of National Poverty Eradication (NAPEP) on Economic Development of Nigeria. An unpublished B.Sc Dissertation of Ebonyi State Unikversity Abakalilki.

Agbiokoro, T.M. (2010). The Impact of National Poverty Eradication (NAPEP) on Economic Development of Nigeria. An unpublished B.Sc Dissertation of Ebonyi State Unikversity Abakalilki.

Federal Office of Statistics (1995).The Nigerian Household. Federal Office of Statistics, Lagos.

Federal Office of Statistics (1999).Poverty Profile for Nigeria: An Analysis of the 1996/97 National Consumer Survey (With reference to 1985 and 1992 surveys). Federal Office of Statistics, Abuja, October.

Kpakol, M. (2011). "Poverty Reduction Programme" Being a contribution of National Coordinator of National Poverty Alleviation Programmes (NAPEP). Channel Television Programme on poverty Alleviation. March.

Obadan, M.I. (2004). "Poverty reduction in Nigeria: The way forward" CBN Economic \& Financial Review, Vol. 39 N0. 4.

Obi, B.O. (2007). "Fiscal Policy and Poverty Alleviation: Some Policy Options for Nigeria" AERC Research Paper 164, African Economic Research Consortium, Nairobi.

Okafor, F.B. (2002). Sample Survey Theory with Applications. AFRO-
ORIS Publication Ltd. University of Nigeria Nsukka.

Owoyele, O.S. (2009). "Assessment of Gender Use of Tricycle in Lagos State" Being a Bachelor of Degree in Transport Planning and Management, Department of Geography and Regional Planning, Faculty of the Social Sciences, Olabisi Onabanjo University, Ago-Iwoye Ogun State, Nigeria

Oyesiku, O.O. (2001). "City Poverty and Emerging Mobility Crisis of the Use of Motorcycle as Public Transport in Nigerian Cities", paper presented at $9^{\text {th }}$ World Conference of Transport Research, Seoul, $22^{\text {nd }}-27^{\text {th }}$ July.

Oyesiku, O.O. and Odufuwa, B.O. (2002). "Gender Perspectives in Travel Behaviour of Motorcycles Passengers in Nigerian Intermediate Cities" in CODATU X, Urban Mobility For All (La Mobililte Urbaine Pour Tous) held in Lome, Togo. $12^{\text {th }}-15^{\text {th }}$ November.

Raji, B.A. and Otun, W.O. (2008). "Analysis of Intra-Urban Traffic Problems in Nigeria: A Study of Lagos Metropolis" Indonesian Journal of Geography. 40(1): 67- 87.

Raji, B.A. (2009). "The Role of Transport in Poverty Reduction" A paper delivered at Olabisi Onabanjo University, the Department of Geography and Regional Planning, on the significance of Transport to the Final Year Students in Geography and Regional Planning, and Transport Planning and Management Programmes, on the $13^{\text {th }}$ September.

Raji, B.A. (2013). Spatio-Temporal Analysis of Pedestrian Traffic in Ikeja Area Lagos, A PhD Thesis submitted to the Department of Geography 
University of Ibadan, Ibadan, Oyo State Nigeria.

Raji, B.A., Oloriegbe, A., and Adeoshun, A.A. (2014). Road Users' Awareness of and Compliance with Pedestrian Crossings in Ikeja Lagos, Nigeria A paper presented at the 3 rd International Conference of Urban and Regional Planning (ICURP14), Urban Agenda: Realities Challenges and Potentials organised by the Department of Urban and Regional
Planning, University of Lagos, Nigeria between 13th-15th October. Sukhatme, P. V., B. V. S., and Asok, C. (1984). Sampling Theory of Surveys with Applications. $3^{\text {rd }}$ ed. Iowa State University Press. Ames, Iowa, USA.

Thomsen, I. (1976). "A Comparison of Approximately Optimal Stratification given ProportionalAllocation with Other Methods of Stratification and Allocation". Metrica, 23(1): 15-25. 